\title{
Distributed Generation Integration to Grid using DG Controlled PQ Theory
}

\author{
Kranthi Kumar Vanukuru, Pakkiraiah B
}

\begin{abstract}
Pollution and far-away location of generation are the main disadvantages regarding bulk power generation from conventional power plants like gas plants, thermal and nuclear power plants. These constraints give scope to look for alternative energy sources reducing pollution and distance of location. Distributed generation $(D G)$ is a viable option to generate power at distribution level without pollution and further reducing transmission line losses due to distance. Sending power from renewable energy sources needs an inverter to be integrated with grid. Inverter also performs the task of harmonic filtering in source components acting as active power filter. This paper presents integration of distributed generation from $P V$ array to grid via an inverter controlled with $D G$ controlled $P Q$ theory. When power is fed from distributed generation, the source power from main grid to load will decrease and this variation is shown in results. MATLAB/Simulink software was used to develop the proposed model and the results are discussed for different cases. Results are presented for two cases where the source current is affected by the load without APF and variable active power to grid with the integration of DG along with APF.
\end{abstract}

Keywords : Distributed generation, DG controlled $P Q$ theory, Integration, Active Power Filter (APF), Grid.

\section{INTRODUCTION}

Environmental conditions, electrical modeling and developments in industries led to new power generation epoch where fat section of power required for load section is fed through extensive induction of distributed resources generally known as distributed generation [DG] [1-3]. Distributed generation is usually located at intermittent positions which are located at the point of consumption. DG is defined as the electrical energy generated by the stand-alone or integrated generation near/at the point of consumption. In the conventional mode of generating the electrical energy at the suitable locations where the sources are available and in the favorable conditions for power generation, which are usually far away from the end-users and the energy, is transmitted to the point of consumption. Unlike to the conventional model, DG is located within the community, industries, corporate buildings and at the major power consumer locations. It encourages renewable energy generation and offers flexibility to power-distribution by

Revised Manuscript Received on September 22, 2019

* Correspondence Author

Kranthi Kumar. Vanukuru, Research Scholar, Department of EEE, Koneru Lakshmaiah Education Foundation, Vaddeswaram, Guntur, A. P., 522 502, India

Pakkiraiah B, Associate Professor, Member IEEE, ISTE, IAENG, Department of EEE, Gokaraju Rangaraju Institute of Engineering and Technology-Autonomous, Bachupally, Hyderabad, Telangana State, 500090 , India sharing the load in the distribution systems. [4]. A photo-voltaic array, wind system, fuel cells, micro turbines, hydro turbines constitutes DG system. The DG system is responsible to feed increased load demand and also meets environmental regulations. The performance of the DG system is mainly based on either the DG system is coupled with synchronous or induction generators or to power electronic converters. DG can be operated in either stand-alone mode of operation or grid connected mode of operation. Stand-alone operation of DG supplies power to local loads,however the power will not be fed to grid. There is no relation between grid and DG system when DG is operated in standalone mode of operation. Furthermore, DG can be operated in grid connected mode where the generated power is fed to the grid to share the part of load section. Grid connected mode of operation comprises multiple DG units of considerable amount of power generation to meet the critical load conditions in order to improve the reliability of the system, significantly where there is a disturbance in the utility supply [5-9]. In a grid connected distributed system, dual active power filters (APFs) are used for DG integration and for the elimination of harmonics in case of Non-linear loads [10]. Design and control of SAPF filter with Synchronous Detection Method (SDM) and compared with the PQ theory [11]. Renewable energy source is integrated with the grid besides maintaining the Power quality of the system [12]. Various Control techniques are discussed for SAPF for improving the quality of Power [13]-[16].

The electrical power system constitutes the generating units at distinguish locations and the distributed load points along with the structure of power components from generation to the end point by keeping the electrical parameters under the permissible values. Stand-alone DG system is simple in configuration, and offers flexibility in dealing with the distribution systems. Besides the all these advantages, it suffers from the continuity of the power supply. Power supply interruption will take place when the system is not connected to grid. In the integrated mode of power system, the level of complexity of integration is high to cope up with the existence grid network. The existed grid system should not be affected with the DG integration. Therefore, DG integrated distribution systems shall meet all the conditions to maintain a healthy power grid system.

In this paper, a DG integrated distributed system dealing with the power quality issues, integrity of the power grid are discussed. This paper presents the integration of DG to grid. DG is operated in grid connected mode where active power from grid is being transferred to grid. When the active power is sent from DG, main source 
power is reduced. PV array is considered to be DG in this paper. DG generates DC type of supply and to integrate this power to grid, DC is to be converted to AC power through interfacing inverter. Inverter is controlled using DG controlled PQ theory in this paper. Inverter acts as an active power filter for filtering out harmonics in source currents when non-linear loads are connected to distribution system. Presented concept was developed using MATLAB/SIMULINK software and results are discussed. Results are presented for two cases where distributed generation sending fixed active power and variable active power to grid.
The schematic arrangement of power system with DG and integrating inverter controlled with DG Controlled PQ Control strategy is illustrated in Fig. 1. In DG controlled PQ theory, DG power is compared with active power component instead of measuring DC-link voltage with reference value in conventional PQ theory. Integrating inverter while acting as inverter sends power to grid from DG also acts as APF filtering out harmonics.

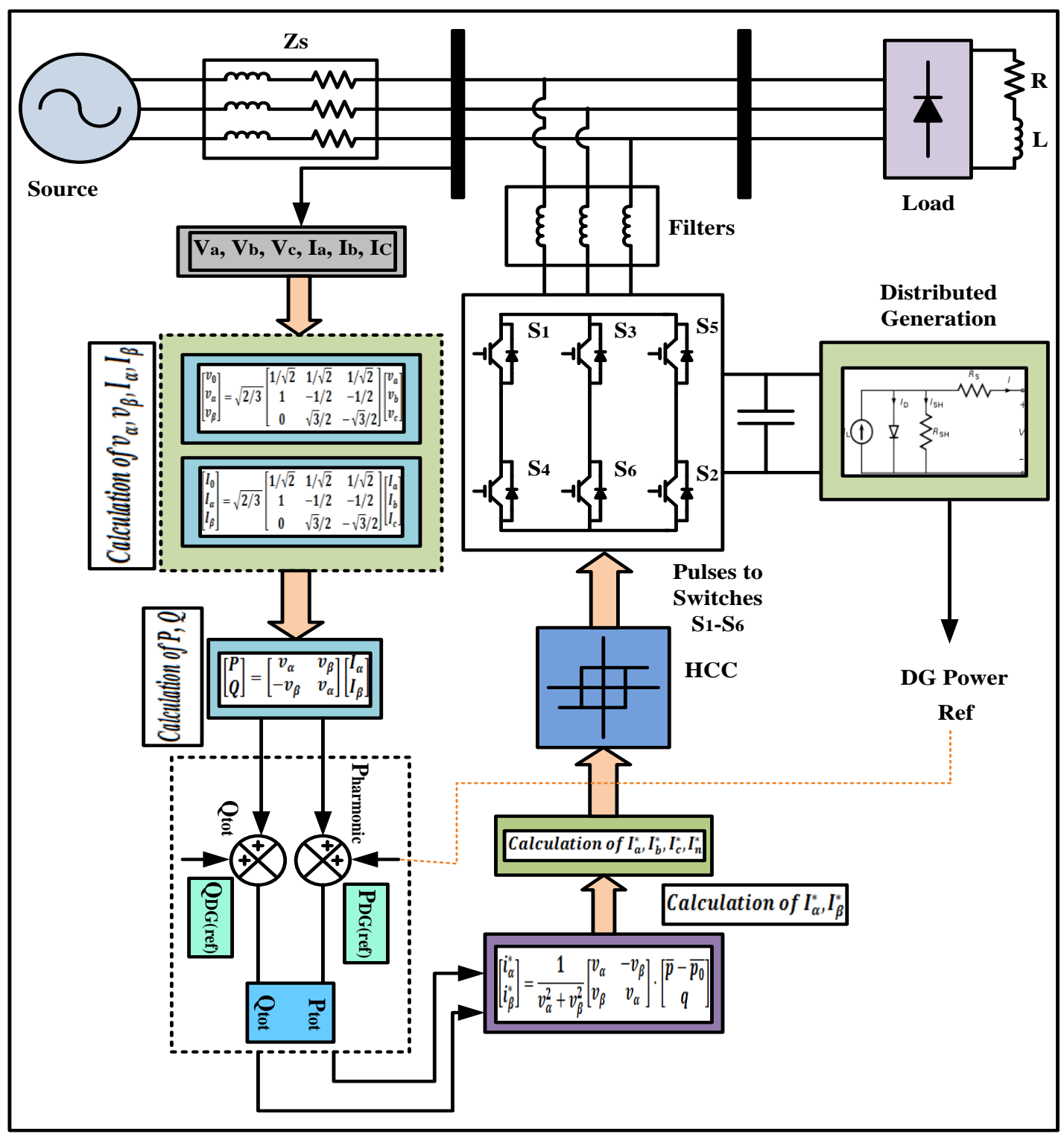

Figure 1: Schematic arrangement of power system with DG and integrating inverter controlled with DG Controlled PQ Control strategy

\section{INTEGRATING INVERTER AS ACTIVE POWER FILTER}

Distributed power generation by the renewable energy sources is very low. Therefore, a cluster of units is interconnected as a single unit. Power flow among the number of units has to be channeled into proper power flow from DG to the grid. The internal disturbances of the DG due to a mismatch of power generation by the individual units have to be controlled. Even though, more number of units accommodates the power generation, still the DG power is relatively low when compared with the grid power. The grid disturbances influence the performance of the DG. Furthermore, the uncertainty and dynamic nature of the distribution system causes disturbances to the DG. All these conditions lead to proper control strategy to maintain the stability of the DG when it is 
operated in grid-connected mode. When non-linear loads are connected to distribution system, non-linearity nature of the load induces harmonics in to source components. Integrating inverter which inverts DC to AC type of supply also works as active power filter when controlled with proper control strategy to filter out harmonics. Non-linear loadsare fed from source through the source impedance. Inverter is a voltage source converter fed from a small DC source. Switches in voltage source converter are triggered from pulses obtained from control circuit.

\section{DG CONTROLLED PQ THEORY}

DG controlled Instantaneous active and reactive power (IARP) theory to control switches in APF by generating gate pulses is shown in figure 3. Initially three-phase line voltages and three-phase currents are measured from the power system line and are transformed in terms of $\alpha$ and $\beta$ voltages and currents by using parks transformation. Then instantaneous powers of both active and reactive component were calculated. Active power component obtained contains fundamental component and the harmonic component.This active power component when passed through high pass filter (HPF) allows only harmonic component of active power. DG power is measured and is compared with calculated active power component and the obtained signal is fed for the calculation of reference components of currents. Reference current signals in $\alpha$ and $\beta$ terms are re-transformed to abc values using inverse parks transformation. The reference current signals are compared with actual line currents to send error signal to hysteresis current controller (HCC) producing gate signals to switches in APF.

\section{SIMULATION RESULTS AND ANALYSIS}

Two different cases are clearly discussed to understand the essence of the Active Power Filter (APF) in order to reduce the effect of unwanted harmonics caused by the Non-linear loads. At first (i) Without DG \& APF under variable load condition to show the effect of Non-linear load on the source current (Is).Secondly (ii) Integrating inverter (APF) with DG sending variable active power is discussed with relevant waveforms.

\subsection{Without DG \& APF under variable load condition}

The power factor angle between source voltage (Vs) and source current (Is). The power factor is not maintained nearer unity as there is a phase difference between Vs and Is. Source current is multiplied with gain to obtain clear view of phase angle and is shown in figure 2.

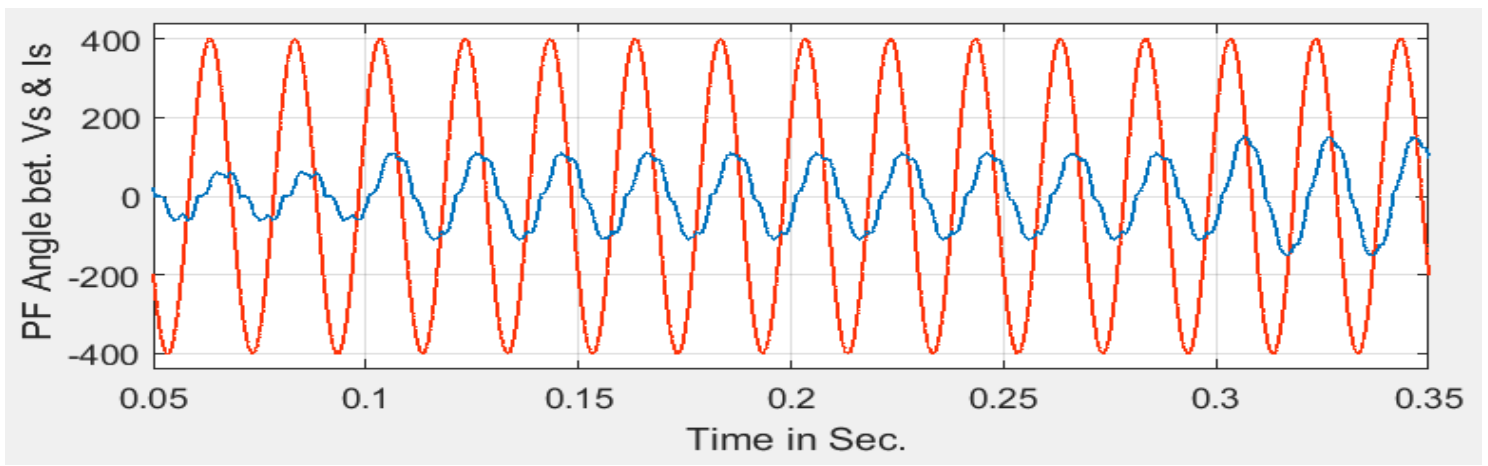

Figure 2: Power factor angle between source voltage and source current

The Simulink result of three-phase source currents, three-phase load voltages and three phase load currents are shown in Fig. 3. Load increases at two different instances, at instant $\mathrm{t}=0.1$ second load increases and the current drawn from the source increases. The load voltage and the load current is deviating from sinusoidal waveform because of the harmonics induced by the non-linear load. It also affects the source current as it is clearly shown in Figure 3. Similarly the current further increases at $\mathrm{t}=0.3$ second due to further increase in the load and the load current is continue to deviate from the sinusoidal waveform because of the harmonics caused by the non-linear load. 

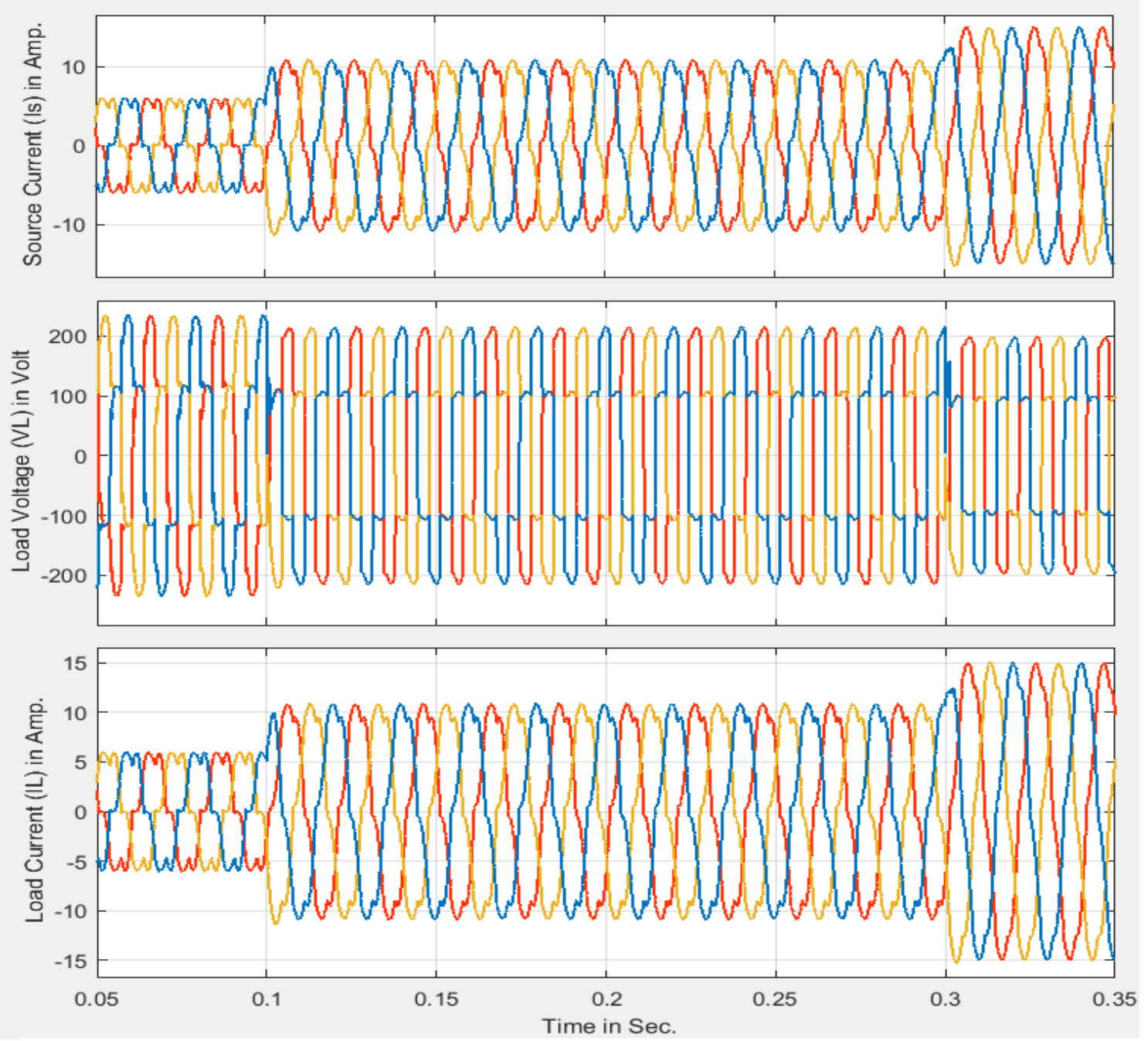

Figure 3: Source current (Is), Load voltage (VL) and Load current (IL)

The THD in load current contains $19.66 \%$ distortion, which samples the given signal over a period of time and divides it into its frequency components as depicted in Fig. 4. It shows the harmonics components which are odd multiples of the fundamental frequency component of $50 \mathrm{~Hz}$. The window shows that there are 5th, 7th, 11th, 13th, 17th and 19th harmonic frequencies will be at $250 \mathrm{~Hz}, 350 \mathrm{~Hz}, 550 \mathrm{~Hz}$, $650 \mathrm{~Hz}, 850 \mathrm{~Hz}$, and $950 \mathrm{~Hz}$ respectively. The ratio of the total harmonics to the value at fundamental frequency times $100 \%$ is the THD of the given load current signal.

Whereas the THD in source current contains $19.65 \%$ distortion which is highly undesirable value as shown in Fig. 5. So, the introduction of the APF with DG brings down the source current harmonics under the nominal value which is explained in the next section. Inverter in required to integrate DG to grid and the same inverter performs the task of filtering.

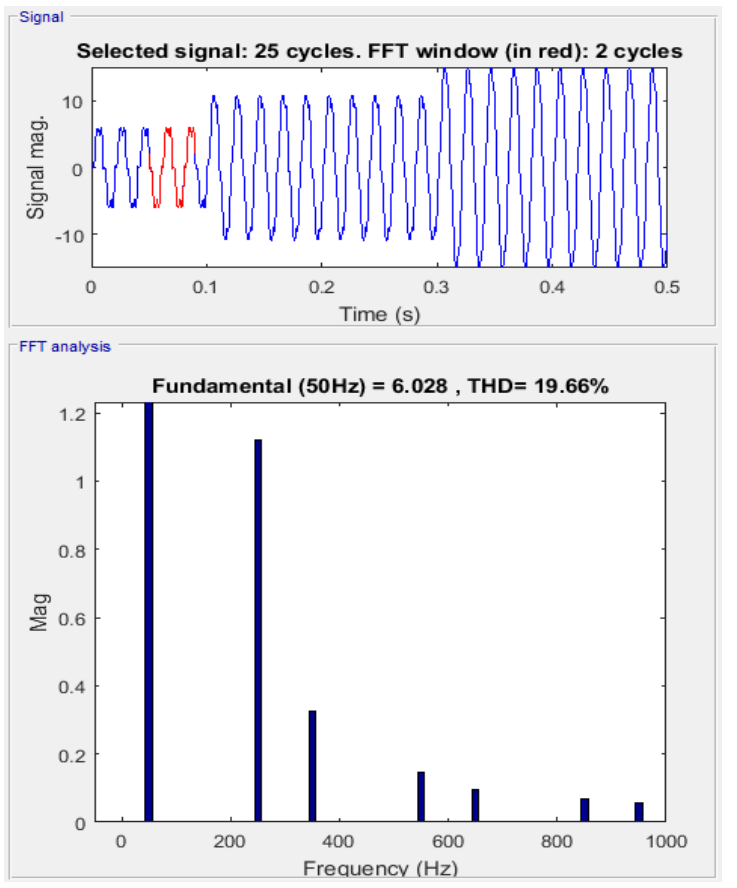

Figure 4: Load Current THD 


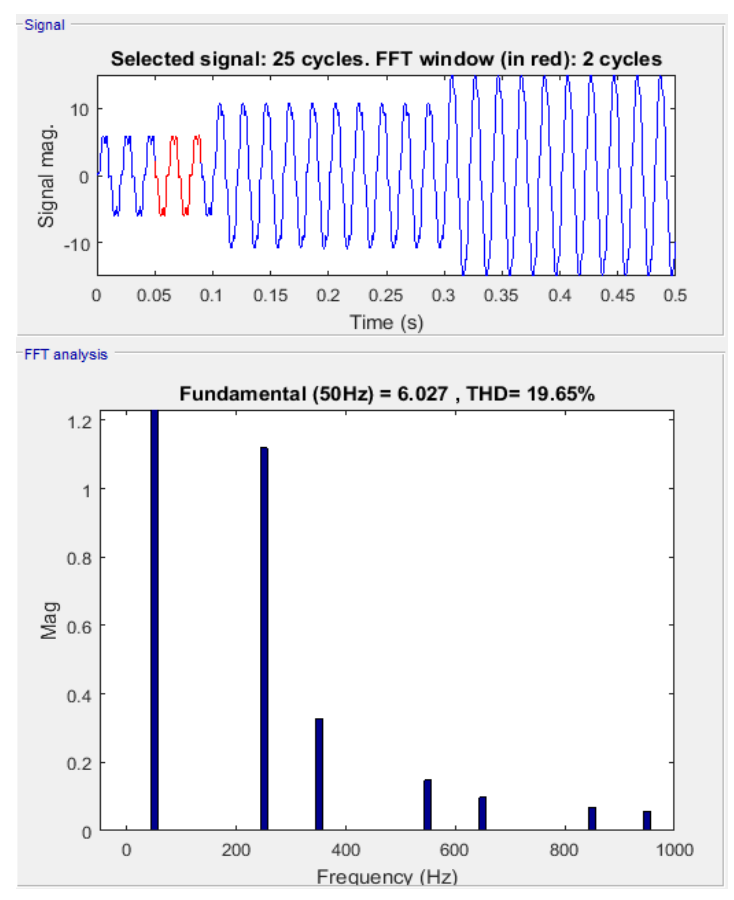

Figure 5: Source Current THD

\subsection{Integrating inverter (APF) with DG sending variable active power \\ The power factor angle between source voltage (Vs) and source current (Is) with APF is illustrated in Fig. 6. As there is no phase difference between source voltage and source current, power factor is maintained nearer unity. Source current is multiplied with gain to obtain clear view of phase angle.}

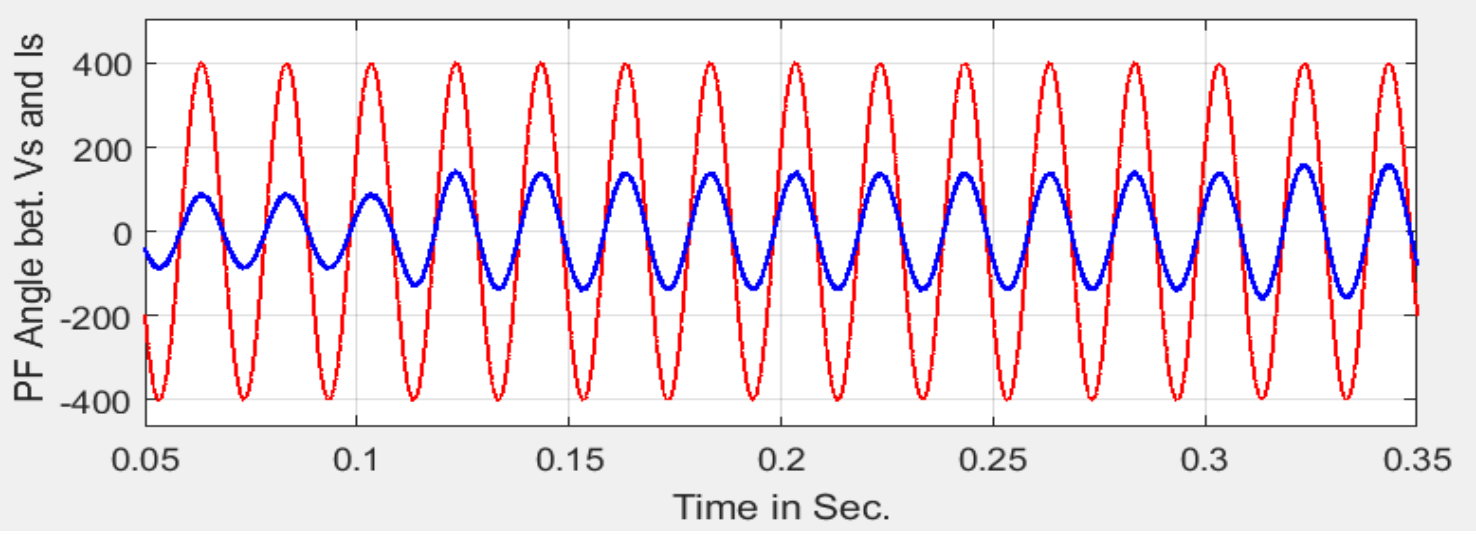

Figure 6: Power factor angle between source voltage and source current (with APF and DG)

The Simulink results of three-phase source currents, load currents and APF currents when the system is with DG sending variable active power is shown in Fig. 7. At instant 0.1 seconds, DG is switched to send active power and thus source current reduces indicating reduction in active power from main source and at the same instant APF current also increases indicating induction of active power to grid. At instant 0.2 seconds, the active power from DG is increased as shown with increased APF current and there is reduction is source current further indicating reduction in active power from main source. Source voltage and source currents are maintained sinusoidal. Since load is of non-linear type, load currents are non-linear currents. The compensating currents from APF induced for compensation of harmonics to make source current sinusoidal are shown. 

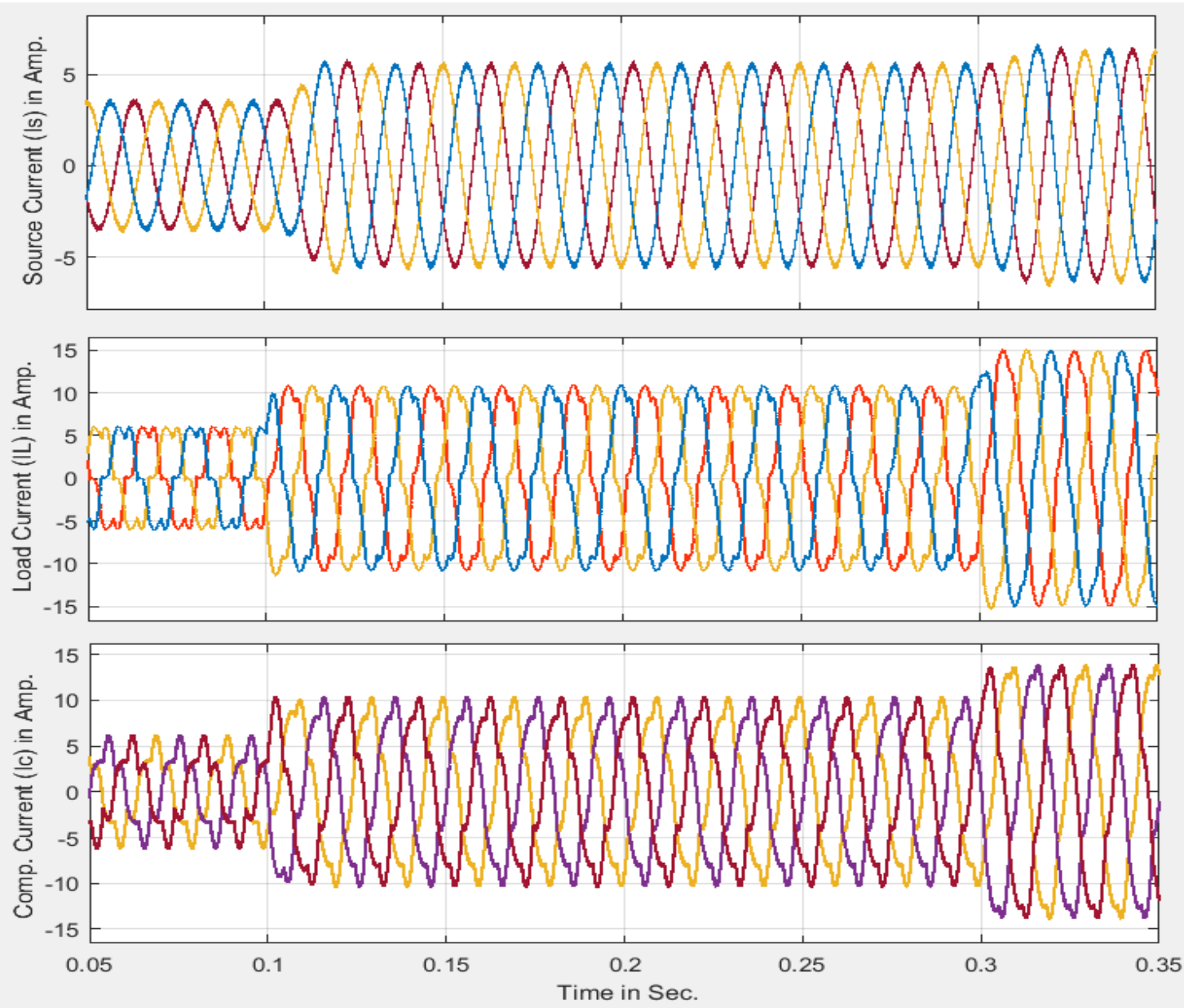

Figure 7: Source current, Load current and Compensation currents (with APF \& DG)
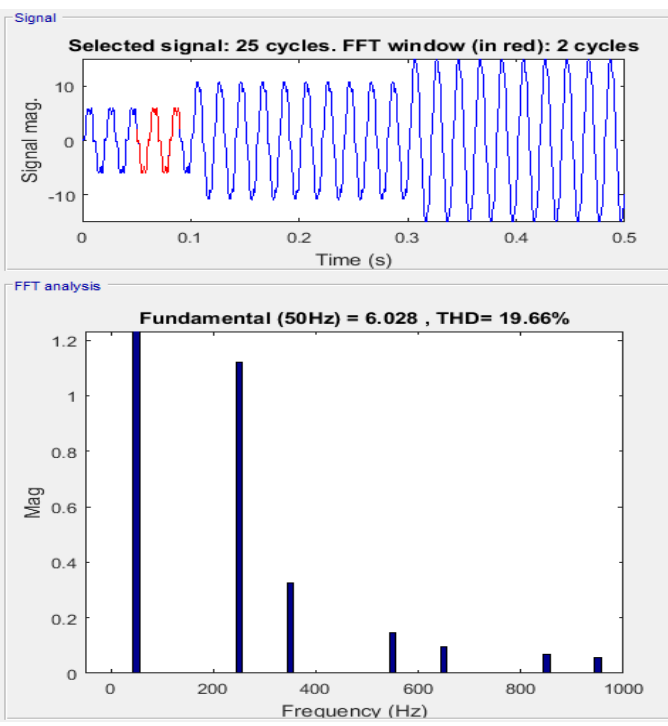

Figure 8: Load current THD

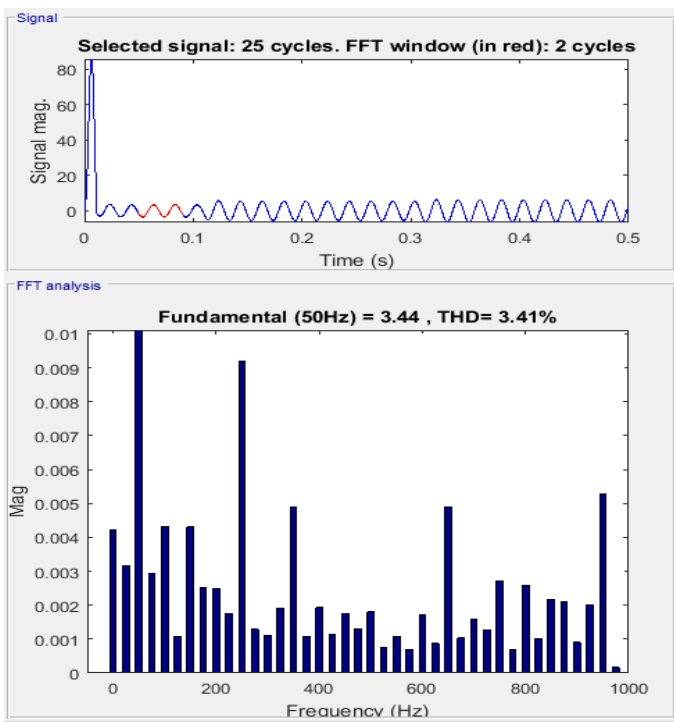

Figure 9: Source current THD (with APF\&DG)

The THD in load current contains $19.66 \%$ distortion as depicted in Fig. 8, whereas the THD in source current contains $3.41 \%$ distortion as shown in Fig. 9, which is well within nominal value. Table 1 represents THD analysis without DG, with DG sending fixed active power and variable active power.

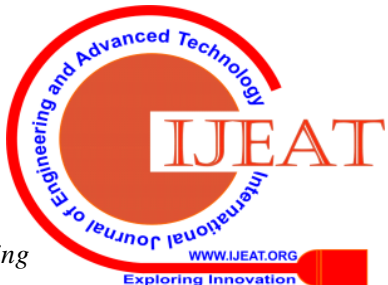


Table 1: THD analysis without DG, with DG sending fixed active power and variable active power

\begin{tabular}{ccc}
\hline THD & Load Current & $\begin{array}{c}\text { Source } \\
\text { Current }\end{array}$ \\
\hline $\begin{array}{c}\text { Without DG \& APF } \\
\text { Integrating Inverter } \\
\text { (APF) with DG }\end{array}$ & $19.66 \%$ & $19.65 \%$ \\
\hline
\end{tabular}

\section{CONCLUSION}

Distributed Generation (DG) seems to be extensively induced in power system due to environmental conditions, electrical modeling and developments in industries. This paper presents integration of distributed generation to grid via an inverter controlled with DG controlled PQ theory. Integrating inverter performs two tasks - one is to invert the power from DG and the other is as APF to filter out harmonics in source components due to non-linear loads. DG controlled control strategy to filter out harmonics was explained in detail. When power is fed from distributed generation, the source power from main grid to load will decrease and this variation is shown in results. The THD content in the source current is reduced to $3.41 \%$ with the use of APF from 19.65 $\%$. Presented concept was developed using MATLAB/SIMULINK software. Results were presented for two cases where distributed generation sending fixed active power and variable active power to grid. THD analysis without DG, system with DG sending fixed active power and variable active power were tabulated and source current distortion was kept under nominal limits in all the cases.

\section{REFERENCES}

1. Fang Z. Peng, "Editorial Special issue on distributed power generation," IEEE Transactions on Power Electronics, vol.19, no.5, pp. 1157-1158, Sep. 2004.

2. F. Blaabjerg, Z. Chen and S. B. Kjaer, "Power electronics as efficient interface in dispersed power generation systems," IEEE Transaction on Power Electronics, vol.19, no.5, pp. 1184-1194, Sep. 2004.

3. B. Maurhoff and G. Wood, "Dispersed generation to reduce power costs and improve service reliability," In Proc. Rural Electric Power Conference, pp. C5/1-C5/7, May 2000.

4. J. Gutierrez-Vera, "Use of renewable sources of energy in Mexico," IEEE Transactions on Energy Conversion, vol.9, no.3, pp. $442-450$, Sept. 1994

5. J. L. Del Monaco, "The role of distributed generation in the critical electric power infrastructure," In Proc. IEEE-Power Engineering Society Winter Meeting, vol.1,pp. 144-145, Jan. 2001.

6. L. Philipson, "Distributed and dispersed generation: addressing the spectrum of consumer needs," In Proc. IEEE-Power Engineering Society Summer Meeting, vol.3,pp. 1663-1665, Jan. 2000.

7. D. Casadei, G. Grandi, R. K. Jardan and F. Profumo, "Control strategy of a power line conditioner for cogeneration plants," In Proc. IEEE-Power Electronics Specialists Conference, vol.2, pp. 607-612, July 1999.

8. Eldo, Cerin, Riya k, Mohazmed Anees s, and Rajiniganth e. "Treatment Of Textile Plant Effluent By Using A Heat Exchanger." international journal of communication and computer technologies 7.supplement 1 (2019), 27-29. Print. Doi:10.31838/ijccts/07.sp01.06

9. Yuvaraj, d., Rojinraju, n.Aravindaswin, Krishnan.k, and Rsteni Reyas. "Design Of Lcu For Reverse Air Bag House In Cement Industry." international journal of communication and computer technologies 7.supplement 1 (2019), 30-32. print. doi:10.31838/ijccts/07.sp01.07

10. Yadiki Rajendra Babu and C. Srinivasa Rao, "A Critical Evaluation of Power Quality Features using Dual APF under Grid Interfaced DG Scheme," International Journal of Electrical Engineering and Computer Science, vol.7, no.2, pp. 322-337, Aug. 2017.
11. Mouna Tali, Ahmed Essadki and Tamou Nasser, "Harmonic Detection Methods of Shunt Active Power Filter under unbalasnced loads," International Renewable and Sustainable Energy Conference,Morocco, 978-1-5090-5713-9/16, Nov. 2016.

12. A. Kavitha, Dr. N. Senthil Kumar and N. Vanaja, "Design and Control of Grid Synchronization of Renewable Energy Sources," International Conference on Circuit, Power and Computing Technologies, Nagercoil, 978-1-5090-1277-0/16, Nov. 2016.

13. Kranthi Kumar. V and B. Pakkiraiah, "Development of Control Techniques for SAPF for Power Quality Enhancement", Journal of Advanced Research in Dynamical and Control Systems, vol.10, no.9, pp. 1900-1907, July 2018.

14. Maheswararao, Ch Uma, YS Kishore Babu, and K. Amaresh. "Sliding mode speed control of a DC motor." 2011 International Conference on Communication Systems and Network Technologies. IEEE, 2011.

15. Sukumar, Durga, Jayachandranath Jithendranath, and Suman Saranu. "Three-level inverter-fed induction motor drive performance improvement with neuro-fuzzy space vector modulation." Electric Power Components and Systems 42.15 (2014): 1633-1646.

16. Yadlapalli, Ravindranath Tagore, and Anuradha Kotapati. "A fast-response sliding-mode controller for quadratic buck converter." International Journal of Power Electronics 6.2 (2014): 103-130. 